\title{
Influence of cyanobacterial diet on Asplanchna predation risk in Brachionus calyciflorus
}

Peter L. Starkweather \& Elizabeth J. Walsh ${ }^{1}$

Department of Biological Sciences, University of Nevada, Las Vegas, NV 89154, USA; ' Department of Zoology, Oregon State University, Corvallis, OR 97331, USA

Hydrobiologia 186/187: 35-38, 1989.

C. Ricci, T.W. Snell and C. E. King (eds), Rotjer Symposium V.

Owing to an unfortunate typesetter's mistake, page 37 of the above issue contains 2 major errors: Table 2 has been printed twice and Table 3 is omitted altogether. The full page as it should have appeared is presented overleaf. The publishers extend their apologies for any inconvenience to the authors and readers. 
Table 2. Influence of prey diet on predator responses of adult $A$. sylvestrii to ovigerous $B$. calyciflorus cultured on diets of either E. gracilis or Anabaena flos-aquae. Numerical values and statistical treatment as in Table 1.

\begin{tabular}{lllll}
\hline $\begin{array}{l}\text { Prey } \\
\text { diet }\end{array}$ & $\begin{array}{l}\text { Attack after } \\
\text { encounter }\end{array}$ & $\begin{array}{l}\text { Capture after } \\
\text { attack }\end{array}$ & $\begin{array}{l}\text { Ingestion after } \\
\text { capture }\end{array}$ & $\begin{array}{l}\text { Ingestion after } \\
\text { encounter }\end{array}$ \\
\hline Euglena & $\begin{aligned} 0.56 \pm 0.24 \\
(0-1.00)\end{aligned}$ & $\begin{array}{r}0.56 \pm 0.27 \\
(0-1.00)\end{array}$ & $\begin{array}{r}0.39 \pm 0.31 \\
(0-1.00)\end{array}$ & $0.12 \pm 0.16$ \\
Anabaena & $\begin{array}{r}0.58 \pm 0.31 \\
(0.19-1.00)\end{array}$ & $\begin{array}{r}0.66 \pm 0.35 \\
(0.14-1.00)\end{array}$ & $\begin{array}{r}0.37 \pm 0.43 \\
(0-1.00)\end{array}$ & $0.14 \pm 0.38$ \\
\hline $\mathrm{p}(\mathrm{K} . \mathrm{W}$.W $)$ & n.s. & n.s. & n.s. & n.s. \\
\hline
\end{tabular}

ingestion after capture than do ovigerous adults. The two reproductive classes do not differ in their probability of capture after attack. The combined probabilities for the entire functional sequence (ingestion after encounter) indicates that, in a given interaction, ovigerous animals are at least three times less likely to be ingested than the non-ovigerous and smaller individuals.

These results led us to use only ovigerous (and therefore somewhat larger and older) prey when examining the effect of prey diet on susceptibility to Asplanchna predation. We wanted to maximize the opportunity for the Brachionus to accumulate any chemical 'signal' which might influence A. sylvestrii behavior and to extend the period of handling of prey (due to their larger size) by individual predators - again, to maximize the possibility of the predators detecting and responding to any such factor.

Table 2 shows that in these experiments prey diet (Euglena vs. Anbabaena) had no significant effect on $B$. calyciflorus vulnerability to predation by $A$. sylvestrii. In neither composite (ingestion after encounter) nor subsidiary behaviors was there any indication that the predator detected or responded to a factor correlated with prey diet. It is also important to note here that we observed no differences in prey size, shape or behavior based on their original diets. Thus, the lack of predator response was not due to confounding factors which might mask an influence based on prey diet.

Asplanchna sylvestrii cohorts fed Brachionus cultured on Euglena have instantaneous population growth rates approximately twice those of matched groups fed Anabaena-cultured prey (Tble 3). This result appears to be due almost exclusively to the differential in net fecundity $\left(R_{o}\right)$, with no significant differences between the two groups in median survivorship $\left(0.5 l_{\mathrm{x}}\right)$ or calculated generation time $(\mathrm{T})$.

Table 3. Influence of prey diet on selected population dynamic parameters of $A$. sylvestrii fed prey (B. calcyciflorus) cultured on diets of either $E$. gracilis or $A$. flos-aquae. Parameters indicated are median survivorship $\left(0.51_{\mathrm{x}}\right)$, net productive rate $\left(\mathrm{R}_{\mathrm{o}}\right)$, generation time $(\mathrm{T})$ and intrinsic rate of increase $(r)$. Values are means for three cohorts, 12-18 animals each \pm s.d. Statistical treatment as in Table 1.

\begin{tabular}{lllll}
\hline \begin{tabular}{l} 
Prey $\begin{array}{l}\text { (Brachionus }) \\
\text { diet }\end{array}$ \\
\cline { 2 - 5 }
\end{tabular} & $0.5 \mathrm{l}_{\mathrm{x}}$ & $\mathrm{R}_{\mathrm{o}}$ & $\mathrm{T}$ & $\mathrm{r}$ \\
\hline $\begin{array}{lllll}\text { Euglena } \\
\text { Anabaena }\end{array}$ & $6.17 \pm 0.95$ & $4.98 \pm 0.86$ & $4.03 \pm 0.15$ & $0.40 \pm 0.05$ \\
\hline $\mathrm{p}(\mathrm{K} . \mathrm{W}$. $)$ & $5.31 \pm 0.08$ & $2.33 \pm 0.96$ & $2.54 \pm 1.80$ & $0.19 \pm 0.14$ \\
\hline
\end{tabular}

